\section{Effect of At-Home Bleaching on Oxygen Saturation Levels in the Dental Pulp of Maxillary Central Incisors}

\author{
Caroline Solda, ${ }^{1}$ Fernando Branco Barletta, ${ }^{2}$ José Roberto Vanni, ${ }_{1}^{1}$ Paula
}

Lambert, ${ }^{2}$ Marcus Vinícius Reis Só, ${ }^{3}$ Carlos Estrela ${ }^{4}$

\begin{abstract}
The present study assessed oxygen saturation $\left(\mathrm{SaO}_{2}\right)$ levels before, during, and after at-home bleaching treatment in the pulps of healthy maxillary central incisors. $\mathrm{SaO}_{2}$ levels were measured in 136 healthy maxillary central incisors using a pulse oximeter. The bleaching protocol consisted of 10\% carbamide peroxide gel placed in individual trays and used for four hours daily for 14 days. $\mathrm{SaO}_{2}$ levels were assessed before bleaching (TO), immediately after the first session (T1), on the 7th day of treatment (T2), on the 15th day (the day following the last session) (T3), and 30 days after completion of the bleaching protocol (T4). Data were statistically analyzed using generalized estimating equations (GEE), Student's $t$ test $(\mathrm{p}<0.05)$ and Pearson's correlation. Mean pulp $\mathrm{SaO}_{2}$ levels were $85.1 \%$ at T0, 84.9\% at $\mathrm{T} 1$, $84.7 \%$ at $\mathrm{T} 2,84.3 \%$ at $\mathrm{T} 3$, and $85.0 \%$ at $\mathrm{T} 4$. Gradual reductions in $\mathrm{SaO}_{2}$ levels were observed, with significant differences $(p<0.001)$ during the course of home bleaching treatment. However, 30 days after the end of the bleaching protocol, $\mathrm{SaO}_{2}$ levels returned to baseline levels. Home bleaching caused a reversible transient decrease in $\mathrm{SaO}_{2}$ levels in the pulps.
\end{abstract}

\author{
'IMED, School of Dentistry, \\ Passo Fundo, RS, Brazil \\ 2ULBRA - Universidade Luterana \\ do Brasil, Canoas, RS, Brazil \\ ${ }^{3}$ UFRGS - Universidade Federal do Rio \\ Grande do Sul, Porto Alegre, RS, Brazil \\ ${ }^{4}$ Department of Stomatology, \\ UFG - Universidade Federal de \\ Goiás, Goiânia, GO, Brazil
}

Correspondence: Prof. Carlos Estrela, Praça Universitária s/ n74605-220, Goiânia, G0, Brasil. Tel: +55-62-32096254.e-mail: estrela3@terra.com.br

Key Words: oxygen saturation, pulp vitality, sensibility test, dental whitening, dental pulp.

\section{Introduction}

Tooth bleaching is a very popular esthetic procedure. Patients who wish to have whiter teeth have increasingly sought this type of treatment, performed either at home or in the office (1). At-home bleaching has been performed using individual trays containing carbamide peroxide gel at low concentrations (10\% and 15\%), used for up to 8 hours daily, for 2 to 6 weeks (2).

However, the diffusion of hydrogen peroxide and its toxic effects on the dentin-pulp complex may cause different degrees of pulp damage, ranging from transient inflammatory response to pulp necrosis (3-5). Discomfort (sensitivity) is a pulp response often reported by patients undergoing tooth bleaching, as a result of aggression to the pulp induced by rapid diffusion of bleaching agent molecules to surrounding tissues (6).

Thermal and electric pulp sensibility tests are commonly used to establish the initial diagnosis of sensitivity and plan treatment, but they involve applying painful stimuli for the stimulation of nerve endings in the dental pulp (7). Also, these pulp sensibility tests may promote false responses depending on pulp status in different clinical situations.

In this sense, assessment of oxygen saturation $\left(\mathrm{SaO}_{2}\right)$ levels has been used to determine vitality and clinical conditions of the dental pulp $(8,9)$. This analysis is based on the vascular supply of oxygen to the pulp rather than on sensitive responses to nerve stimuli (8-10). Innovative resources such as laser doppler flowmetry and pulse oximetry have been used to assess pulp vascularization.
Pulse oximetry, in particular, has emerged as a promising resource in endodontics, capable of measuring $\mathrm{SaO}_{2}$ levels in the dental pulp $(8,11,12)$ and accessible to both general and specialist practitioners. Several studies have described the use of pulse oximeters to determine pulp $\mathrm{SaO}_{2}$ levels in cases of periodontal disease, incomplete root formation, dental trauma, differential diagnosis of pulpitis and pulp necrosis (11-13).

The objective of this study was to assess $\mathrm{SaO}_{2}$ levels in healthy maxillary central incisors subjected to at-home bleaching treatment. The null hypothesis was that changes in $\mathrm{SaO}_{2}$ levels would occur as a result of the at-home tooth bleaching protocol.

\section{Material and Methods}

\section{Sample Selection}

This prospective intervention clinical study was approved by the local research ethics committee (protocol \# 1.786.631). All participants were informed of treatment procedures, advantages and disadvantages of at-home tooth bleaching, and all signed an informed consent form prior to inclusion in the study. A total of 68 patients were selected according to sample size calculation, considering a power of 90\% (significance of 5\%) in a repeated-measures design. Taking into consideration a design effect (clustercorrelated data) of 2.0, a sample size of 136 maxillary central incisors was determined. The patients selected for this study were volunteers of both sexes, aged 19 to 36 years, seeking treatment at Centro de Estudos Odontológicos 


\section{Meridional (CEOM).}

The diagnosis of pulp conditions was determined through anamnesis and clinical examination. During anamnesis, both medical and dental history data were collected. Oral clinical examination was performed with emphasis on maxillary central incisors, and included visual inspection, percussion, palpation, mobility, periodontal insertion, and cold test with Green Endo Ice refrigerant spray $\left(-26.2{ }^{\circ} \mathrm{C}\right.$; Coltene, Hygienic, $\left.\mathrm{OH}, \mathrm{USA}\right)$ to determine the presence of pulp sensibility. Patients were asked to assign a score to the sensitive stimulus (pain) using an analog scale ranging from 0 to 10 , where 0 corresponded to the absence of pain and 10 to severe pain. The response was considered negative after $15 \mathrm{~s}$ of application of the refrigerant spray. In these cases, a new test was conducted after a 2-min interval. The cold test was repeated 30 days after completion of the bleaching protocol.

The following inclusion criteria were taken into consideration: patients with healthy maxillary central incisors, with intact crowns, good oral health (absence of pain to percussion, palpation, or periodontal disease), absence of systemic diseases (e.g., decompensated diabetes, cancer treatment, leukemia, uncontrolled hypertension, the gingival margin, anatomically following the gingival contour. Three bleaching gel tubes (10\% carbamide peroxide, Whiteness, FGM, Joinvile, SC, Brazil) were handed to each patient, and they were instructed on the correct amount of gel to be placed in the tray: one drop in each tray space corresponding to each tooth. Trays should be used for 4 $\mathrm{h}$ daily (they should not sleep with the trays) during 14 consecutive days. Patients were advised to brush their teeth using common toothpaste containing fluoride (without desensitizers) and to use dental floss before placing the tray.

\section{Pulp Sensitivity}

Cold sensibility testing was performed after isolation using cotton rolls and an ejector by a specialist in endodontics. A refrigerant gas (-26.2 ${ }^{\circ} \mathrm{C}$, Green Endo Ice) was applied to the middle third of the buccal surface of the tooth under evaluation using a cotton pellet and dental tweezers.

Participants were invited to use a diary to record any occurrence of tooth sensitivity over the course of the athome bleaching treatment, and to rate it using a 5-point analog scale, with scores ranging from 0 to 4 , as follows: 0 , no sensitivity; 1 , mild sensitivity; 2 , moderate sensitivity; 3 , considerable sensitivity; and 4 , severe sensitivity (14). Patients were also requested to immediately inform the research team of the occurrence of sensitivity, so that the levels of $\mathrm{SaO}_{2}$ could be assessed in the first 24 hours of the symptom.

\section{Pulse Oximetry}

$\mathrm{SaO}_{2}$ levels were measured by a previously calibrated examiner specialized in endodontics using a portable pediatric pulse oximeter (BCI 3301, Smiths Medical PM extra roots or bone condensations. In addition, patients should not have performed tooth bleaching in the last 5 years. Exclusion criteria were maxillary central incisors with previous root canal treatment, fistula, edema, darkened crowns, fluorosis, tetracycline staining, loss of periodontal insertion, probing depth $>3 \mathrm{~mm}$, gingiva recession, mobility, history of occlusal or dental trauma, negative vitality test, smokers, and pregnant or breastfeeding women.

\section{At-Home Bleaching Protocol}

Individual trays were prepared with a reservoir cut approximately $1 \mathrm{~mm}$ far from

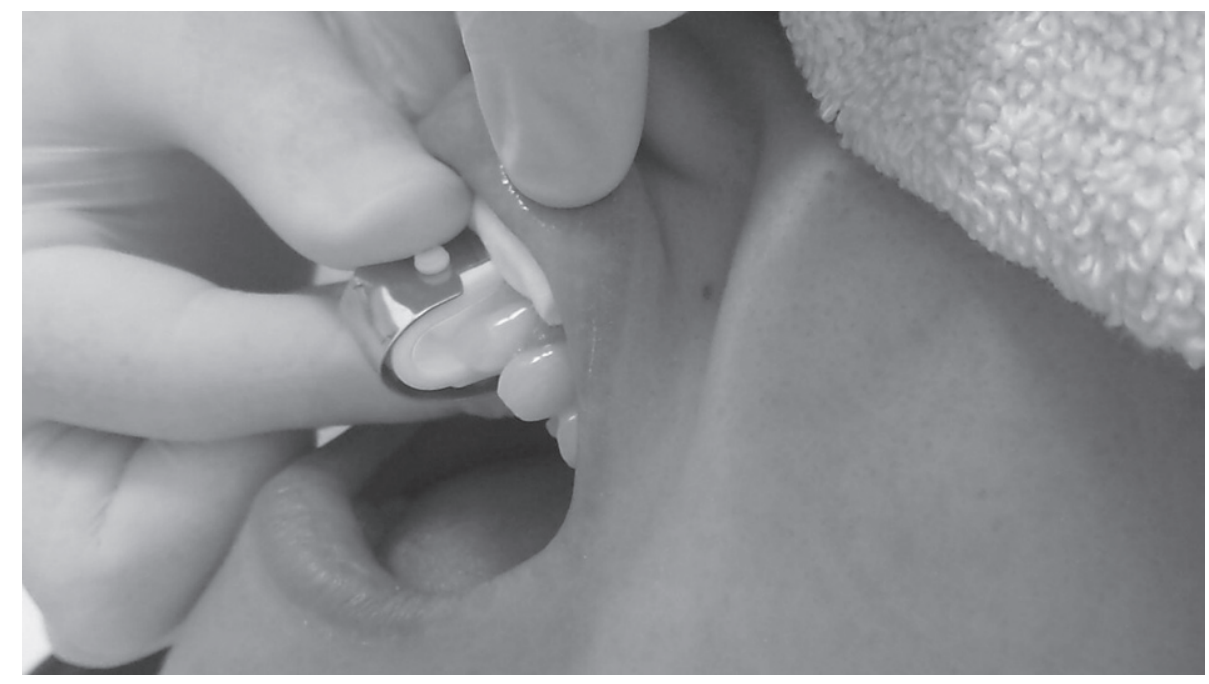

Figure 1. Parallel position of the connector in relation to the tooth for the assessment of oxygen saturation levels 
Inc., Waukesha, WI, USA) equipped with 3026 sensors (for fingers). A stainless steel adapter was fabricated specifically for this study. It was designed to attach the pulse oximeter to patients' teeth, ensuring that the sensor's diodes would remain parallel to each other during measurements (15), so as to allow the light-emitting diodes to remand thus the infrared light to pass through the tooth crown correctly (Fig. 1).

With relative isolation, the sensor was attached to the incisors using a connector, which did not touch the tooth, specifically developed for this tooth type, so as to allow the light-emitting diodes to remain parallel to one another (15) and thus the infrared light to pass through the tooth crown correctly (Fig. 1). With the sensor positioned on the tooth to be tested, a face towel was placed on the patient's face to avoid the interference of other sources of light (11). Patients were told to avoid moving their heads during the $\mathrm{SaO}_{2}$ measurements because the device was very sensitive. Three measurements were obtained, the first one $30 \mathrm{~s}$ after the sensor was adapted to the tooth, the second 30 seconds after the first measure was recorded by the device, and the third one after another $30 \mathrm{~s}$. Measurements were made at four time points, as follows: before application of the bleaching gel (T0), immediately after the first bleaching session (T1), on the 7 th day of treatment (T2), on the 15th day (the day following the last session) (T3), and 30 days after completion of the bleaching protocol (T4). Also, in the event of a complaint of sensitivity, $\mathrm{SaO}_{2}$ levels

Table $1 . \mathrm{SaO}_{2}$ levels (\%) measured in fingers and teeth

\begin{tabular}{lccc}
\hline $\mathrm{SaO}_{2}(\%)$ & $\mathrm{N}$ & Mean & $\mathrm{SD}$ \\
\hline Finger & 68 & $96 \%$ & 1.5 \\
Tooth 11 & 68 & 84.9 & 1.8 \\
Tooth 21 & 68 & 85.4 & 1.9 \\
All teeth & 136 & 85.1 & 1.9 \\
\hline
\end{tabular}

$\mathrm{SaO}_{2}=$ oxygen saturation; $\mathrm{SD}=$ standard deviation. were assessed in the first $24 \mathrm{~h}$ of the symptom. Following tooth measurements, $\mathrm{SaO}_{2}$ levels were also measured at the patients' index fingers. $\mathrm{SaO}_{2}$ levels obtained from 10 endodontically treated maxillary central incisors restored with composite resin were used as negative control.

\section{Statistical Analysis}

Data were expressed as mean, standard deviation, median, minimum and maximum. For the analysis of $\mathrm{SaO}_{2}$ levels and heart rate, a GEE model was used, taking into consideration the cluster effect observed for teeth from the same patient over time. Differences were expressed using means and their corresponding 95\% confidence intervals. Simple comparison of two means was performed

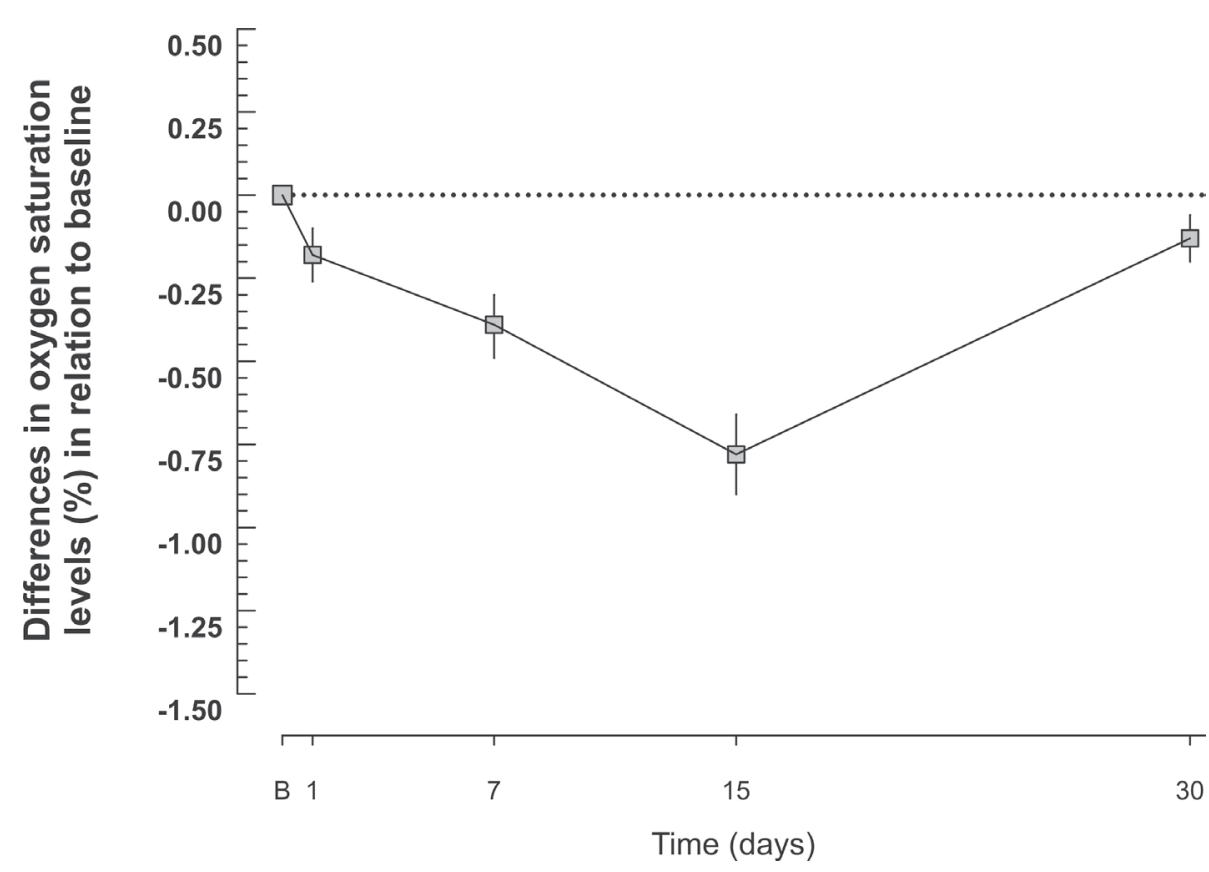

Figure 2. Distribution of oxygen saturation levels (\%) measured on dental pulps at different time points.
Table 2. Distribution of $\mathrm{SaO}_{2}$ levels (\%) measured on dental pulps (n =136) at different time points

\begin{tabular}{lcccc}
\hline Time & ${\text { Mean } \mathrm{SaO}_{2}(\%)} \mathrm{SE}$ & $\mathrm{p}$-value & $95 \% \mathrm{CI}$ \\
\hline T0 & $85.1^{\mathrm{a}}$ & 0.21 & - & - \\
T1 & $84.9^{\mathrm{a}}$ & 0.19 & $<0.001$ & -0.26 to -0.10 \\
T2 & $84.7^{\mathrm{a}}$ & 0.18 & $<0.001$ & -0.49 to -0.30 \\
T3 & $84.3^{\mathrm{a}}$ & 0.18 & $<0.001$ & -0.90 to -0.66 \\
T4 & $85.0^{\mathrm{a}}$ & 0.19 & $<0.001$ & -0.20 to -0.06 \\
\hline
\end{tabular}

95\% $\mathrm{CI}=95 \%$ confidence interval; $\mathrm{SaO}_{2}=$ oxygen saturation; $\mathrm{SE}=$ standard error; $\mathrm{T} 0$ = baseline; $\mathrm{T} 1$ = immediately after the first bleaching session; $\mathrm{T} 2=7$ days of treatment; $\mathrm{T} 3=15$ days of treatment; $\mathrm{T} 4=$ 30 days after completion of at-home bleaching treatment. a Means estimated in an adjusted model. 
using the Student $t$ test. Linear correlations were assessed using Pearson's correlation coefficient. Significance was set at $\alpha=0.05$. Analyses were performed using the Statistical Package for the Social Sciences (SPSS) version 22.0.

\section{Results}

A total of 127 patients were screened to obtain a final sample of 68 patients for the at-home bleaching protocol (there were 13 losses along the study period due to incorrect use of the bleaching gel and non-attendance to $\mathrm{SaO}_{2}$ measurements; these subjects were replaced). Ten patients were selected for use as negative control.

Of the 68 participants, 27 were male and 41 female. Mean age was 26 years. Table 1 shows the $\mathrm{SaO}_{2}$ levels obtained in fingers and teeth. The 10 maxillary central incisors endodontically treated and restored with composite resin showed $0 \%$ of $\mathrm{SaO}_{2}$.

No significant statistical correlations were observed between heart rate (beats per minute) and body $\mathrm{SaO}_{2}$ levels measured at either the index fingers or teeth (Pearson's correlation coefficient; $r=-0.02 ; p=.85$ ).

With regard to pulp $\mathrm{SaO}_{2}$ levels measured at $\mathrm{TO}$ vs. T1, a reduction of $0.2 \%$ was observed; at $\mathrm{T} 2$, another $0.2 \%$ reduction was found, and $-0.4 \%$ at $\mathrm{T} 3$. At $\mathrm{T} 4, \mathrm{SaO}_{2}$ levels were similar to baseline levels (Fig. 2). From T0 to T1, T2 and T3, gradual reductions were observed, reaching a maximum reduction of $0.8 \%$ in pulp $\mathrm{SaO}_{2}$ levels, at a statistically significant difference $(p<0.001)$ (Table 2$)$.

Of the 68 patients included in the sample, 22 (32\%) reported mild $(n=15)$ and moderate $(n=7)$ sensitivity. Of these, 18 informed the research team within $24 \mathrm{~h}$ of the onset of the symptom. Between the $2 \mathrm{nd}$ and the 7 th days of treatment, $\mathrm{SaO}_{2}$ levels measured in patients reporting sensitivity were similar to the measures obtained at $\mathrm{T} 1$. Between the 8th and the 14th day, values were similar to those observed at T2. No statistically significant differences were found in $\mathrm{SaO}_{2}$ levels at the pulps of teeth 11 and 21 , respectively $(p=0.182 ; p=0.391)$ when compared to baseline values.

\section{Discussion}

The limitations associated with the subjective nature of thermal and electric pulp sensibility tests have stimulated studies with pulse oximetry, a technique that is capable of detecting changes in dental pulp status. Studies involving pulse oximetry in endodontics have shown that this is a promising resource with potential use in clinical practice, as it is non-invasive, easy and simple to apply, and yields objective measures $(11,12,13,16-20)$. However, there is a scarcity of studies on pulp response in teeth subjected to bleaching. In the present study, the hypothesis that $\mathrm{SaO}_{2}$ levels change during dental bleaching treatment was confirmed.

The selection of patients was rigorous, controlling for possible confounding factors and including only healthy teeth from young patients - patient age may directly influence pulp $\mathrm{SaO}_{2}$ levels (13). Another important aspect in patient selection was the exclusion of patients using systemic medications, as it is known that certain medications may interfere with pulp $\mathrm{SaO}_{2}$ levels (21). Finally, patients were advised not to use desensitizing toothpastes during the course of the bleaching protocol. With these criteria, the authors believe to have controlled for variables that might possibly influence the results of the study.

In the present study, 68 patients with a mean age of 26 years showed mean baseline pulp $\mathrm{SaO}_{2}$ of $85.1 \%$ in maxillary central incisors. This result is in line with some previous studies $(17,18)$ that showed similar pulp $\mathrm{SaO}_{2}$ levels in this same tooth group. Conversely, in other investigations $(18,19)$, pulp $\mathrm{SaO}_{2}$ levels of $91.29 \%$ and $79.3 \%$ were reported. Differences may be interpreted and explained by the different methodologies adopted in the studies, by the small sample sizes (17 patients), as well as by the fact that $\mathrm{SaO}_{2}$ data were collected at one time point only. However, small differences in $\mathrm{SaO}_{2}$ levels are not clinically relevant; follow-up time is a determinant when $\mathrm{SaO}_{2}$ levels are below 80\% (12). Indeed, young patients with pulp $\mathrm{SaO}_{2}$ levels below $80 \%$ should be followed up clinically and radiographically (12), as $\mathrm{SaO}_{2}$ thresholds are associated with clinical conditions affecting the dental pulp and may lead to pulp necrosis asymptomatically (12).

In the present study, only slight differences were observed between the $\mathrm{SaO}_{2}$ levels obtained at the two maxillary central incisors of the same patient at baseline: on tooth 11 , mean $\mathrm{SaO}_{2}$ was $84.9 \%$, and on tooth $21,85.4 \%$ (Table 1). These values may be attributed to anatomical differences between these tooth types, e.g., enamel and dentin thickness (22).

A decline in pulp $\mathrm{SaO}_{2}$ levels was observed, with a reduction of $0.2 \%$ at T1, $0.2 \%$ at T2, and $0.4 \%$ at T3. From T0 to T1, T2 and T3, a gradual reduction was observed, reaching $0.8 \%$ of reduction in pulp $\mathrm{SaO}_{2}$, at a statistically significant difference in relation to baseline values ( $p<0.001)$ (Table 2$)$. However, when $\mathrm{SaO}_{2}$ was assessed 30 days after completion of the bleaching protocol (T4), pulp $\mathrm{SaO}_{2}$ values were found to have returned to baseline levels (T0) (Fig. 2). Clinically, this reduction did not result in changes in pulp status, as $\mathrm{SaO}_{2}$ levels soon returned to normal levels (85\%) (23). This same finding was reported in a previous study (24), in which the authors assessed the effect of intraoral radiation on pulp $\mathrm{SaO}_{2}$ levels in the long term and concluded that small changes to pulpal microcirculation were temporary.

Application of 10\% carbamide gel for short periods of time has demonstrated that treatment effectiveness is 
maintained regardless of bleaching gel concentration (25). Conversely, long periods of contact between 10\% carbamide peroxide gel and the tooth surface may increase the risk of sensitivity without improving tooth whitening results (14).

With regard to sensitivity, $32 \%$ of the patients reported either mild $(n=15)$ or moderate $(n=7)$ sensitivity. No significant differences in $\mathrm{SaO}_{2}$ levels were found in the pulps of teeth 11 and 21 (left and right) $(p=0.182 ; p=0.391$, respectively) in these patients. When sensitivity was reported between the 2 nd and the 7th days of treatment, $\mathrm{SaO}_{2}$ levels were compared to the measures obtained at $\mathrm{T} 1$ to assess any differences. Patients reporting sensitivity between the 8 th and the 14 th day had the values compared to T2 measures. Of the 22 patients who complained of sensitivity, four did not seek assistance within the first $24 \mathrm{~h}$ of the symptom to assess $\mathrm{SaO}_{2}$ levels; however, at $\mathrm{T} 4$, pulp $\mathrm{SaO}_{2}$ levels in these patients were similar to those observed at baseline. The results indicate that the sensitivity reported by these patients did not cause changes in pulp $\mathrm{SaO}_{2}$.

The $\mathrm{SaO}_{2}$ levels observed in this study reinforce previous findings (4) that demonstrated that pulp alterations provoked by bleaching were reversible and returned to normal levels within 2 weeks after completion of the bleaching treatment. Pena \&t Raton (2) failed to find significant differences in the degree of whitening with different gel concentrations, and recommended the use of gels with lower concentrations (10\% and 15\%). From a different standpoint, it is important to emphasize the tooth group studied, namely, maxillary central incisors. In mandibular incisors, clinical response to sensitivity may be stronger due to the reduced thickness of enamel and dentin layers. Costa et al. (5) showed that a concentration of 38\% hydrogen peroxide provokes irreversible damage to the pulp of mandibular incisors. The high concentration of this gel may have been the cause of sensitivity in teeth with reduced enamel and dentin thicknesses. Thus, bleaching gel concentration should ideally not exceed 10\% (2).

No significant statistical correlation was found between the levels of body $\mathrm{SaO}_{2}$ levels and heart rate on the patient's index finger and teeth $(r=-0.02 ; p=0.85)$. This finding is in line with previous investigations $(17,19,26)$.

Pulse oximetry is consolidated as a reliable, clinically relevant resource, easy to handle and with a low cost, offering safe results to general and specialist practitioners in endodontics and helping in the diagnosis of different clinical conditions (18). The clinical implication observed in this study was that at-home tooth bleaching with $10 \%$ carbamide peroxide used for $4 \mathrm{~h}$ daily caused a decrease in $\mathrm{SaO}_{2}$ levels in the pulps of maxillary central incisors in the early stages of treatment, returning to baseline values 30 days after treatment completion. Although pulse oximetry is an effective method for the diagnosis of pulp vitality, it has some limitations inherent to the use of these devices.

\section{Resumo}

Este estudo verificou o grau de saturação de oxigênio $\left(\mathrm{SaO}_{2}\right)$ pulpar antes, durante e após o clareamento dental caseiro em incisivos centrais superiores hígidos. 0 nível de $\mathrm{SaO}_{2}$ foi verificado em 136 incisivos centrais superiores hígidos usando oxímetro de pulso. A técnica de clareamento empregou peróxido de carbamida $10 \%$ em moldeira individual por quatro horas diárias durante 14 dias. Os niveis de $\mathrm{SaO}_{2}$ foram analisados antes do clareamento (T0), imediatamente após a primeira sessão (T1), no sétimo dia de tratamento (T2), no décimo quinto dia (um dia após a última sessão) (T3) e 30 dias após o término do clareamento dental (T4). A análise estatística utilizou o modelo de equações de estimações generalizadas (GEE), teste $t$ de Student $(p<0,05)$ e correlação de Pearson. Os niveis médios de $\mathrm{SaO}_{2}$ pulpar foram 85,1\% em T0, 84,9\% em T1, 84,7\% em T2, 84,3\% em T3 e $85,0 \%$ em T4. Foi observada uma redução gradual dos niveis de $\mathrm{SaO}_{2}$, com diferenças significantes $(p<0,001)$ durante o clareamento dental caseiro. No entanto, 30 dias após o término do clareamento dental, houve retorno aos valores iniciais. 0 clareamento dental caseiro provocou uma diminuição transitória reversivel no grau de $\mathrm{SaO}_{2}$ pulpar.

\section{References}

1. Almeida LC, Riehl H, Santos PH, Sundfeld ML, Briso AL. Clinical evaluation of the effectiveness of different bleaching therapies in vital teeth. Int J Periodontics Restorative Dent 2012;32:303-309.

2. Alonso de la Peña $V$, López Ratón M. Randomized clinical trial on the efficacy and safety of four professional at-home tooth whitening gels. Oper Dent 2014;39:136-143.

3. Trindade FZ, Ribeiro APD, Sacono NT, Oliveira CF, Lessa FC, Hebling J, et al. Trans-enamel and trans-dentinal cytotoxic effects of a 35\% $\mathrm{H} 2 \mathrm{O} 2$ bleaching gel on cultured odontoblast cell lines after consecutive applications. Int Endod J 2009;42:516-524.

4. Fugaro JO, Nordahl I, Fugaro OJ, Matis BA, Mjör IA. Pulp reaction to vital bleaching. Oper Dent 2004;29:363-368.

5. Costa CAS, Riehl H, Kina JF, Sacono NT, Hebling J. Human pulp responses to in-office tooth bleaching. Oral Surg Oral Med Oral Pathol Oral Radiol Endod 2010;109:e59-e64.

6. Faria-E-Silva AL, Nahsan FP, Fernandes MT, Martins-Filho PR. Effect of preventive use of nonsteroidal anti-inflammatory drugs on sensitivity after dental bleaching: a systematic review and meta-analysis. J Am Dent Assoc 2015;146:87-93.

7. Trowbridge HO, Franks M, Korostoff E, Emling R. Sensory response to thermal stimulation in human teeth. J Endod 1980;6:405-412.

8. Estrela C, Serpa GC, Alencar, AHG Bruno KF, Barletta FB, Felippe WT, et al. Oxygen saturation in the dental pulp of maxillary premolars in different age groups - Part 1. Braz Dent J 2017;28:573-577.

9. Dastmalchi $N$, Jafarzadeh $H$, Moradi S. Comparison of the efficacy of a custom-made pulse oximeter probe with digital electric pulp tester, cold spray and rubber cup for assessing pulp vitality. J Endod 2012;38:11821186.

10. Moule AJ, Moule CA. The endodontic management of traumatized permanent anterior teeth: a review. Aust Dent J 2007;52(1 suppl):S122-S37.

11. Giovanella LB, Barletta FB, Felippe WT, Bruno KF, de Alencar AH, Estrela C. Assessment of oxygen saturation in dental pulp of permanent teeth with periodontal disease. J Endod 2014;40:1927-1931.

12. Setzer FC, Kataoka SHH, Natrielli F, Gondim-Junior E, Caldeira CL. Clinical diagnosis of pulp inflammation based on pulp oxygenation rates measured by pulse oximetry. J Endod 2012;38:880-883.

13. Liao , Ye W, Yue J, Zhao X, Zhang L, Zhang L, et al. Self-repaired process of a traumatized maxillary central incisor with pulp infarct after horizontal root fracture monitored by laser doppler flowmetry combined with tissue oxygen monitor. J Endod 2017;43:1218-1222.

14. Cardoso PC, Reis A, Loguercio A, Vieira LC, Baratieri LN. Clinical effectiveness and tooth sensitivity associated with different bleaching times for a 10 percent carbamide peroxide gel. J Am Dent Assoc 2010;141:1213-1220. 
15. Stella JP, Barletta FB, Giovanella LB, Grazziotin-Soares R, Tovo MF, Felippe WT, et al. Oxygen saturation in dental pulp of permanent teeth: difference between children/adolescents and adults. J Endod 2015:41:1445-1448.

16. Caldeira $\mathrm{CL}$, Barletta $\mathrm{FB}$, Ilha $\mathrm{MC}$, Abrão $\mathrm{CV}$, Gavini G. Pulse oximetry: a useful test for evaluating pulp vitality in traumatized teeth. Dent Traumatol 2016;32:385-389.

17. Bargrizan M, Ashari MA, Ahmadi M, Ramezani J. The use of pulse oximetry in evaluation of pulp vitality in immature permanent teeth. Dent Traumatol 2016;32:43-47.

18. Bruno KF, Barletta FB, Felippe WT, Silva JA, Gonçalves de Alencar AH, Estrela C. Oxygen saturation in the dental pulp of permanent teeth: a critical review. J Endod 2014;40:1054-1057.

19. Calil E, Caldeira CL, Gavini C, Lemos EM. Determination of pulp vitality in vivo with pulse oximetry. Int Endod J 2008;41:741-746.

20. Gopikrishna V, Tinagupta K, Kandaswamy D. Comparison of electrical, thermal, and pulse oximetry methods for assessing pulp vitality in recently traumatized teeth. J Endod 2007;33:531-535.

21. Shetty PK, Satish SV, Kilaru K, Chakravarthi Ponangi K, M Luke A, Neshangi $S$. An in vivo evaluation of the change in the pulpal oxygen saturation after administration of preoperative anxiolytics and local anesthesia. J Dent Res Dent Clin Dent Prospects 2016;10:31-35.
22. Macha AC, Vellini-Ferreira F, Scavone-Junior H, Ferreira RI. Mesiodistal width and proximal enamel thickness of maxillary first bicuspids. Braz Oral Res 2010;24:58-63.

23. Radhakrishnan S, Munshi AK, Hegde AM. Pulse oximetry: a diagnostic instrument in pulpal vitality testing. J Clin Pediatr Dent 2002;26:141145.

24. Kataoka SH, Setzer FC, Gondim-Junior E, Fregnani ER, Moraes CJ, Pessoa $O F$, et al. Late effects of head and neck radiotherapy on pulp vitality assessed by pulse oximetry. J Endod 2016;42:886-889.

25. Basting RT, Amaral FL, França FM, Flório FM. Clinical comparative study of the effectiveness of and tooth sensitivity to $10 \%$ and $20 \%$ carbamide peroxide home-use and 35\% and 38\% hydrogen peroxide in-office bleaching materials containing desensitizing agents. Oper Dent 2012;37:464-473.

26. Estrela C, Oliveira KS, Alencar AHG, Barletta FB, Estrela CR, Felippe WT. Oxygen saturation in the dental pulp of maxillary and mandibular molars - Part 2. Braz Dent J 2017;28:704-709.

Received March 12018 Accepted June 21, 2018 